\title{
STUDENT TEACHER DESIGNED-TASKS IN FACILITATING HIGHER ORDER THINKING SKILLS AT MICROTEACHING CLASSES OF UIN SUNAN AMPEL SURABAYA
}

\author{
Hamidah Salam ${ }^{1}$, Mokhamad Syaifudin ${ }^{2}$, Irma Soraya ${ }^{3}$ \\ English Education Department \\ UIN Sunan Ampel Surabaya \\ Surabaya, Indonesia \\ hamidahsallam@gmail.com ${ }^{1}$, msyaifudin@uinsby.ac.id ${ }^{2}$, mozafyr@yahoo.com ${ }^{3}$
}

\begin{abstract}
Since higher order thinking skills become one of education goals, the thinking skills become essential for teachers in teaching it to learners. In Bloom's taxonomy, the cognitive domain, Analyze, Evaluate, and Create level are defined as higher order thinking skills. In constructing the tasks, there will be several ways used to construct task in higher order thinking level. This study focuses on identifying student teacher designed-tasks in facilitating higher order thinking skills in their Microteaching classes as their preparation before going to internship. This study used qualitative method and checklist as the instrument. In particular, 20 lesson plans were analyzed to identify the tasks designed by the student teachers. In order to support the data, the students were interviewed. Based on the findings and the discussion, the student teacher designed-tasks that can facilitate higher order thinking skills are in the level 4 and 6 of Bloom's cognitive domain. As a conclusion, tasks that are designed by the student teacher in UIN Sunan Ampel Surabaya can facilitate higher order thinking skills in the level 4 and 6 of Bloom's cognitive domain by presenting principles of Brookhart's. Thus, it can be a model for students of English Teacher Education Department in designing task to facilitate higher order thinking skills and as authentic material in teaching assessment task in the discipline.
\end{abstract}

Keywords - Higher Order Thinking Skills, Bloom's Taxonomy Revised Version, Task.

\section{INTRODUCTION}

There are several rules owned by the teachers. One of them is as the knowledge transmitter. If the role of the teacher is to transmit the knowledge to the learners, the students' role is to acquire all the transmitted knowledge. This is how the teachers provide and facilitate the learning objective so the students can acquire the knowledge.

To know the learning outcomes of the students, a teacher need to conduct an assessment. This occurs since in education, assessment is an essential process. [1] Assessment can involve testing, measuring, collecting, combining information and providing feedback. Good assessment design will give the teacher clear outcomes to interpret in the form of score or feedback. In assessment for learning, feedback is needed to improve and develop students' ability. It means that good assessment will give useful information about students' progress. [2] That useful information is used to decide whether the learning objective can be continued or repeated.

In assessing the students, the teacher may give activities and tasks in order to achieve the learning objectives. What the teachers want the student to learn is learning objective. Assessment also needs to be in line with the learning objective so the learning objective can be judged as success or fail outcomes. The assessment of Indonesia in 2013 curriculum stated that it used authentic assessment rather than traditional assessment. It is because the authentic assessment can facilitate the teachers more than the traditional one. [3] Authentic assessment will help the teachers in gaining much information related to the students' improvement. J. Mihael O' Malley and Lorraine Valdez Pierce stated that authentic assessment is multiple types of assessment that can show the students' learning, accomplishment, motivation and attitudes on instructionally-relevant classroom activities. [3] The authentic assessment will provide the assessment in higherorder thinking skills as well. It is based on J. Mihael O' Malley and Lorraine Valdez Pierce' explanation that authentic assessment has several characteristics; (1) constructed response, (2) Higher order thinking, (3) Authenticity, (4) Integrative, (5) Process and product, and (6) Depth versus breadth. [3]

Becoming one of the characteristics of authentic assessment, higher order thinking skills is one of important skills. As the educational goal, higher order thinking skills need to be introduced to the students in order to prepare them facing the real problem. It is aimed to train the students to think more complex in facing problem in the real world. Asking the students to think more complex means requiring them to think critically and creatively and solve problem. [4] Krulik and Rudnick stated that there is four level of thinking in general; recall thinking, basic thinking, critical thinking and creative thinking. [5] While in Bloom's taxonomy, higher 
order thinking skills is on $4^{\text {th }}, 5^{\text {th }}$, and $6^{\text {th }}$ level; analyze, evaluate and create.

Designing task with higher order thinking skills is important to do so the educational goal can be achieved. When the teachers can provide tasks correctly by following the principles and facilitate higher order thinking skills as well, automatically they help the students to earn good outcomes and train them to think in higher order level.

The teachers are expected to design task in higher order thinking skills so the students can have the skill. The teachers' competence in designing the task will be a matter since it deals with the learning objectives. This case is seen interestingly by the researcher to conduct a research to know how teachers' candidate or student teachers design their task. Therefore, this study focuses on how the student teachers design task to facilitate higher order thinking skills by fulfilling some principles.

\section{LITERATURE}

As the educational goal, higher order thinking skills need to be introduced to the students in order to prepare them facing the real problem. Many experts defined higher order thinking skills in many kinds of definitions. The thinking level that considered as higher order thinking skills are critical and creative thinking. FJ King, Ludwika Goodson and Farank Rohani, stated that higher order thinking skills include critical, logical, reflective, metacognitive and creative thinking. [6] In the journal "Strategies for Improving Higher Order Thinking Skills in Teaching And Learning Of Design And Technology Education" by C.C Chinedu added that analyzing information to distinguish the problem, evaluating the problem and creating new practical solution are involved as higher order thinking skills. [7] As the conclusion and simply define, higher order thinking skills are complex thinking skills; the thinking skills that use complex or multiple thinking activities. Further, the activity such as analysis, evaluate, decide a solution, solve a problem and be creative are the example of complex thinking skills. Those thinking activities use more than one thinking activity. According to Susan M. Brookhart that defined higher order thinking skill in the simple definition, higher order thinking skills include (1) transfer, (2) critical thinking and (3) problem solving. [8]

Additionally, higher order thinking skills also showed in Bloom's taxonomy in the 4, 5 and 6 level. Those are Analyze, Evaluate, and Create by revision of David R. Krathwohl. This is the revised version of Bloom's taxonomy: [9]

TABLE I. BLOOM'S TAXONOMY REVISED VERSION

\begin{tabular}{|c|c|c|}
\hline \multicolumn{3}{|c|}{ Cognitive Process Domain } \\
\hline Category & Definition & Cognitive Process \\
\hline Remember & $\begin{array}{c}\text { (Regaining relevant } \\
\text { knowledge from long- } \\
\text { term memory) }\end{array}$ & $\begin{array}{c}\text { Recognizing } \\
\text { Recalling }\end{array}$ \\
\hline Understand & (Determining the & Interpreting \\
& meaning of Instructional & Exemplifying \\
& messages) & Classifying \\
& & Summarizing \\
& & Inferring \\
\hline
\end{tabular}

\begin{tabular}{|c|c|c|}
\hline Apply & $\begin{array}{c}\text { (Carrying out or using a } \\
\text { procedure in a given } \\
\text { situation) }\end{array}$ & $\begin{array}{c}\text { Comparing } \\
\text { Explaining }\end{array}$ \\
\hline Analyze & $\begin{array}{c}\text { Executing } \\
\text { Implementing } \\
\text { detecting how the parts } \\
\text { relate to one another) }\end{array}$ & $\begin{array}{c}\text { Differentiating } \\
\text { Organizing } \\
\text { Attributing }\end{array}$ \\
\hline Evaluate & $\begin{array}{c}\text { (Making judgments } \\
\text { based on criteria and } \\
\text { standards) }\end{array}$ & $\begin{array}{c}\text { Checking } \\
\text { Critiquing }\end{array}$ \\
\hline Create & $\begin{array}{c}\text { (Putting elements } \\
\text { together to form a } \\
\text { creation or make an } \\
\text { original product) }\end{array}$ & $\begin{array}{c}\text { Generating } \\
\text { Planning } \\
\text { Producing }\end{array}$ \\
\hline
\end{tabular}

There are also several principles to construct task in higher order thinking skills: a) using introductory material (provide resource material), b) using novel material (present material that has not given in the learning process), and c) managing cognitive complexity and difficulty separately. [8]

\section{RESEARCH DESIGN AND METHOD}

\section{A. Aim and RQs}

As focused on student teacher designed-tasks in facilitating higher order thinking skills, there is "What is the cognitive domain level of student teacher designed-tasks in facilitating higher order thinking skills based on Bloom's taxonomy?"

\section{B. Subject}

The data that was used in this study was the task item that was designed by student teachers in their microteaching class. This was used to answer the entire research questions. Dealing with the task that needed for this research, the student teachers' lesson plans are collected. This documents are obtained from student teacher of English Teacher Education Department in Sunan Ampel State Islamic University who were enrolling Microteaching classes in even semester academic year 2017/2018. In addition, there are 9 classes of Microteaching class which each class will have 13-14 students as the maximum. Those classes are lectured by four different lecturers. From those 9 classes, the researcher focuses only on 7 classes with 2 different lecturers. This is because those 7 classes are really available in participating this study. The student teachers in those classes are asked to do teaching practice in both 2013 and KTSP curriculum with complete version of lesson plan or RPP based on the Curriculum guidelines. The researcher collects all 2013 curriculum lesson plan from those 7 classes that are designed only for Senior High School. With the Senior High School designed-lesson plan, the researcher expected the student teacher design their lesson plan in high level of cognitive domain. Since, the student of Senior High School are believed to have much more background knowledge rather than Junior High School students.

\section{Instrument and Procedure}

Specifically, documents in this research are the collected lesson plans of student teachers. The task in those lesson plans 
will be the most important instrument for this research. Those tasks are used as the basic data in analyzing how the student teachers facilitate higher order thinking skills. After the lesson plans are collected, to answer the first and the second research question, the researcher uses checklist. There are two different checklists for one research question. The first checklist used Bloom's taxonomy revised version that is already discussed in the previous session. Continuing analysis to the research question will be based on the principles of Brookhart's theory. The checklist is modified from three basic principles.

\section{Method of Data Analysis}

For answering the research question, the researcher analyzed the data by identify the learning objective of the lesson plan then, analyzing it with Bloom's taxonomy. After that, the researcher did deep analysis with Brookhart's theory. Then, the researcher related the findings to the theory to make an interpretation.

\section{FINDINGS AND DISCUSSION}

\section{A. Cognitive Domain Level of Student Teacher Designed- Tasks in Facilitating Higher Order Thinking Skills.}

In case of finding the cognitive domain level of student teacher designed-tasks that facilitate higher order thinking skills, the researcher did several steps; collect the learning objectives, analyze the learning objective based on Bloom's taxonomy and analyze task items from selected higher order thinking skills learning objective.

According to the data, the student teacher designed-tasks can facilitate higher order thinking skills for 57\%. Meaning that from seven learning objectives obtained, there are four tasks that can facilitate higher order thinking skills. Before discussing more about the level of task based on the cognitive domain of Bloom's taxonomy, the researcher needs to explain the found tasks.

From seven learning objectives, there should be seven tasks provided. In fact, one of seven learning objectives did not provide any task to be assessed as stated in the learning objective. In the other words, the student teacher here could not know whether the learning objective was achieved or not. Thus, there were only six tasks that can be analyzed. In analyzing the task, it is analyzed for each task item or question. From those six tasks, five of them were designed as constructing response task with one single task item whereas the other one was designed as constructing response task with five task items. In total, there are ten task items from those six task.

Based on the data above, it can be seen that there are only four task items that facilitate higher order thinking skills. The data shows that two task items are in the Create level while another two task items are in the Analyze level. However, the rest of task items are in the low level of thinking skills; five task items in Remember level and one task item in Understand level. The data shows that from three upper level of cognitive domain, Evaluate level is not used by the student teachers while Create and Analyze level has the same number of level used in the cognitive domain.

\section{Facilitate Higher Order Thinking Skills}

a) Level 4; Analyze

In this Analyze level, there are two task items that show analyze-thinking skills. As in Analyze level, there are three cognitive processes that are included here; differentiating, organizing, and attributing.

This task asked the students to arrange the jumble paragraph into good descriptive text. The Student F here provided jumble paragraph of descriptive text about Bedugul Lake, Bromo Mountain, Komodo Island, and Raja Ampat in the envelop. Then, the Student F gave blank paper as a place for sticking the jumble paragraph into good arrangement of descriptive text.

The other task in Analyze level is also in the Organizing cognitive process. Similar to the previous task, the instruction was not written properly in the students' worksheet. The students were provided worksheet of outline table while the student teacher gave instruction orally. This task item was included as producing since the teacher's instruction clearly stated "make (produce) the outline".

b) Level 6; Create

In this level, Create also has three cognitive processes; generating, planning, and producing. All the data found as create here are producing thinking.

Firstly, this task facilitated higher order thinking skills as stated in the lesson plan by stating operational verb "make" in the topic "private letter".

The students were asked to write a private letter freely; the Student E did not provide any specific topic for writing a private letter. Here, the proper worksheet was also not provided by the student teacher. So, the instruction to do the task was orally stated. The student teacher provided post card as the paper to write the letter.

Secondly, another task item that facilitates higher order thinking in producing something was similar to the first one. Here, the students were asked to "make" dialog. Different from the previous task, this task provided some situations for a topic in making a dialog. Yet, the teacher also did not provide proper worksheet with the written instruction. So, the instruction was orally stated.

As stated by Brown, that the assessment task needs to be in line with the learning objectives. [10] It is used to check whether the students can achieve the learning objectives or not. After conducting the assessment task, the teacher will check and interpret the students' work in order to continue or repeat the material. Therefore, it can be concluded that the task designed should be based on the learning objectives.

When the tasks are in higher order thinking level, the learning objectives also need to be in higher level. Collecting twenty lesson plans, there were twenty-seven learning objectives obtained. From those twenty-seven learning objectives, the learning objectives that were included as higher order thinking level were only four learning objectives. In the 
other words, it was only $15 \%$ learning objectives that were potential in facilitating task in higher order thinking skills.

The finding shows that there are 57\% tasks that can facilitate higher order thinking skills. In the other words, there are four tasks that can facilitate higher order thinking skills from seven learning objectives. Those tasks can facilitate higher order thinking skills in the Analyze and Create level only since there is no student teacher who designed the learning objectives or tasks in the Evaluate level.

In Analyze level, Student D and F could facilitate tasks on this level even though Student F's learning objective is actually in the Remember level; lower order thinking skills. Her task was asking the students to arrange the paragraph into good descriptive text. Arranging the sentences or paragraph is included as organizing. In these cognitive processes, one of the alternative terms is finding coherence. [10] In process of arranging, the students were asked to match and find coherence to construct good descriptive text. The students will identify the sentences (elements) of the paragraph and recognize how the sentences or paragraph fit together. [10]

Fortunately, the given texts were new, meaning that those texts had not been introduced or discussed in the learning process. Thus, the Analyze thinking process could be achieved, hopefully. Further, this task could be more challenging if each long paragraph for each descriptive text was divided or cut into two or three pieces. In the other words, a paragraph with four to five sentences was better to be more than one cutting paper. So, it would lead the students to think more on how those sentences are related.

Furthermore, another task from Student D about making outline, it also indicated Analyze level; Organizing as well. As stated before that Outlining is another term for Organizing. In making the outline, the students were asked to find a biography text freely. The students could decide whoever they want. After reading the biography text, the students were asked to make an outline. Here, those activities were depicted Organizing since the students identify and relate how the sentences (main idea) of each paragraph can fit together. [9]

Moreover, if those tasks referred to the definition of higher order thinking skills, those facilitated the students to think critically. In arranging the text and making an outline, the students tried to identify the relevance and importance ideas from each sentence and find out the logical connections between ideas in each sentence. Those activities (identify the relevance and understand the logical connections) are critical thinking activities. [12]

The other two tasks facilitated higher order thinking skills in the Create level. Those tasks asked the students to produce something such as dialog conversation and a private letter. The product is actually not a matter since the product can be conceptual (such as a list of tentative hypotheses) or physical (painting). [8] The main point here is that the students create something. Discussing about creating something, the reason why "making an outline" task is not included as Create level was because the task was not creating or constructing something. The students were asked to determine the coherent element from each paragraph in a biography text. It is similar to the example of Anderson and Kratwohl about students are asked to make an outline of presented report. [8]

Further, the Student A and Student E here used the operational verb "make" as their learning objectives and instruction task. Additionally, the tasks challenge the students to use their imagination. [12] The task "making a private letter" gave students opportunity to use their imagination on the topic since it's free writing. When it dealt with creativity, the student teachers here could facilitate the students to think creatively. As defined that higher order thinking skills include critical, logical, reflective, metacognitive and creative thinking. [6] Further, Student D in Analyze level with making an outline task, asked the students to look for the biography from the internet. She also asked the students to make notes for important information before creating the outline. Those activities were one of the ways to support the students in being creative. Brookhart explained that creative students will find "source material" for ideas in several different ways such as media, people and events. [8] To sum up, the tasks in Analyze and Create level can facilitate the students to think critically and creatively.

Then, dealing with the principles of constructing tasks in higher order thinking skills, the student teacher deigned-tasks also have fulfilled several principles of Brookhart's. There are six principles that are modified from three basic principles. Here are the details for the four tasks that can facilitate higher order thinking skills:

\section{a. The task presents something to think about (Resource material)}

From four task that can facilitate higher order thinking, the task that can present resource material are only two tasks by Student A and Student F. The resource provided material by the student teachers were descriptive text and situation. Those resource materials are used as stimulus. [4] It was used as the basic in answering the question. It is believed that by presenting stimulus, the task item will promote higher order thinking skills. [4] The resource material can be varied such as pictures, tables, diagrams, passages or text such as poem or poetry and short movie or video. In findings, from examples above, the Student $\mathrm{A}$ and Student $\mathrm{F}$ presented situation and text as the stimulus. As explained, the resource material or introductory material is used as something to think about for students. [4] So, the students would answer the questions based on the text or resource material presented. Resource material in the form of situations which were provided by Student A was also included as text. The text here has a broad meaning, it includes written text, situation, speech, documentary or sort of event. [8]

b. The task asks the students to give response/opinion or to extend their knowledge.

In providing and designing task, the assessment format may be varied. It can be in multiple choices, constructed-response or performance assessment. [8] Constructed-response or essay is believed as one of ways to promote higher order thinking skills. [3] This is 
because by constructing a response, the students can construct their own sentences by their own words. In giving response to a task item, the students may be asked to give comment or opinion by writing one or more sentences or extended essay. [3] Further, from four tasks that can facilitate higher order thinking skills, the three tasks used this assessment format. Meaning that, these are tasks that ask the students to give response. Here, the students were asked to give response in the form of a brief comment in dialog conversation, private letter, and outline. In making dialog conversation, private letter, and outline, the students are given opportunity to apply their knowledge or information rather than recall what they have learnt. [3] In the other words, by providing constructed response task, the students were given opportunities to recall their previous knowledge, related it to the new situation, planned what they will do for the new situation and applied it to the new situation; the students could use their creativity in completing the task. In short, three of four student teachers here promoted higher order thinking skills by providing opportunity for students to construct responses based on what they have learnt.

c. The task challenges the learners.

This principle is fulfilled by all four tasks. In the other words, the four tasks can challenge the learners in facilitating higher order thinking skills. As discussed before that the tasks need to challenge the learners to think logically, be open-minded, seek alternative or be innovative, and use imagination. [12] Here, the student teachers could present tasks that ask students to do so. For example, Student E presented tasks that asked the students to use their imagination. Her task was asking the student to make a private letter. This task would give an opportunity for students to use their imagination to create private letter since the topic was not limited.

d. The task presents something new that students have not learn in the class (New material)

Here, all four tasks that considered facilitate higher order thinking skills are fulfilled this principle. Presenting new material here means the material in the task have not introduced or used in the learning process.

[8] This does not mean the task will have different material from the learning objectives but the task presents something new in topic or theme; the context will still the same as the learning objectives.

\section{e. The task has rubric that intends to assess higher} order thinking skills.

In contrary with the previous principle, this principle are only fulfilled by two tasks. There are only Student A and Student E who provided the tasks with the rubric of thinking skills. As constructing typical assessment task, rubric is needed to score the students' result and as feedback. Since the task was designed to assess student' thinking skills, the rubric that is specifically assessed thinking skills was also needed. In assessing Analyze level, for example, focusing on the main idea, the rubric may be the idea, evidence, and explanation. [8] If the task is focused on the creation of students, the creativity may be added in the rubric. [8] The criteria for rubric can be added or removed based on the teachers' need.

\section{f. The task is in the 4,5 , or 6 level of Bloom's taxonomy.}

In this principle, all of four tasks are in the tree upper cognitive domain levels. By having one of tree upper cognitive domain level of Bloom's, the tasks are hoped to promote higher order thinking skills. As discussed before that those three upper levels are higher order thinking level. [8] The student teacher used operational verb in their tasks; make, make an outline and rearrange. The verb "make" indicated Create level since it created something, while make an outline and rearrange task here indicated Analyze level. The other two tasks were in the lower level of thinking; Remember and Understand. In fact, there was no student teacher who designed their learning objectives in the Evaluate level. In designing learning objectives, the student teachers were freely to decide their own learning objectives. Thus, each cognitive domain level would not always be shown in the learning objectives.

For further discussion, the fact that the tasks in higher order thinking skills were seldom found, it can be related to the student teachers' understanding about Bloom's taxonomy, thinking skills as well as higher order thinking skills, it may also related to how they can design lesson plan. Those understanding would give impact on how they decided learning objectives and assessments. The researcher could say that the student teachers still needed to study more about Bloom's taxonomy and its level since the student teachers still cannot put the thinking process of their tasks in line with the thinking process of learning objectives.

Furthermore, as the six characteristics described, from six students, there was only one student who presented all characteristics. Student A could present the task in line with the learning objective with the characteristics follows. In contrary, in the interview, Student A explained that she did not know about higher order thinking skills. She also explained that she did not understand what Bloom's taxonomy was; she only knew the term. Here, the finding showed that Student A even did not know about Bloom's and higher order thinking skills, she could design the task in higher order thinking skills by presenting the task with several characteristics described above. In the other words, not only Student A but also all the students need to be more aware about these issues. The student teachers not only need to aware of these issues but also need to know how they apply their understanding in designing the learning objective and tasks.

\section{CONCLUSION}

In case of identifying the cognitive domain level of Bloom's, the student teacher designed-tasks can facilitate higher order thinking skills in the level 4 and 6 only for 57\%; Analyze and Create level since there is no learning objective and task in Evaluate level. From ten task items, the tasks in 
the Analyze level are only two task items while the tasks in the Create level are 2 task items.

In relation to the six principles of constructing task in higher order thinking skills, from those four tasks, there is only one task that can present all six principles. The six principles are presenting resource material, asking the students to construct response, challenging the learners, presenting something new to the learners, having rubric for thinking skills and in the upper level of cognitive domain.

\section{REFERENCES}

[1] Centre for Educational Research and Innovation. Assessment for Learning; Formative Assessment.

[2] Norcini, John. "Criteria for Good Assessment; Consensus and Recommendation from the Ottawa 2010 Conference". Medical Teacher. Vol.33. 2013.

[3] O' Malley ,J. Michael, and Lorraine Valdez Pierce. Authentic Assessment For English Language Learners. California : Longman, 1996.
[4] Laily , Nur Rochmah and Asih Widi Wisudawati. "Analisis Soal Tipe Higher Order Thinking Skill (HOTS) Dalam Soal UN Kimia Rayon B Tahun 2012/2013". Kaunia. Vol.11 No.1, April 2015.

[5] Ariandari, Weindy Pramita. Mengintegrasikan Higher Order Thinking dalam Pembelajaran Creative Problem Solving. SEMINAR NASIONAL MATEMATIKA DAN PENDIDIKAN MATEMATIKA UNY 2015.

[6] King, FJ, Ludwika Goodson, and Farank Rohani. Higher Order Thinking Skills; Definition, Teaching Strategies, Assessment.

[7] Chinedu , C.C, Y. Kamin and Olabiyi O.S. 2015. "Strategies for improving Higher Order Thinking Skills in Teaching and Learning of Design and Technology Education". Journal of Technical and Training. Vol.7 No. 2. December 2015.

[8] Brookhart, Susan M. How to Assess Higher-order thinking skills in your classroom. United States of America: ASCD Publication, 2010.

[9] Anderson, L. W. et.al., A Taxonomy For Learning, Teaching And Assessing. New York: Longman, 2001.

[10] Brown, H. Douglas. Language Assessment. USA: Longman, 2004.

[11] Lau, Joe Y. F. An Introduction to Critical Thinking and Creativity. USA: Wiley, 2011.

[12] ACARA Australian Curriculum Assessment and Reporting Authority. (http://www.australiancurriculum.edu.au/GeneralCapabilities/criticaland-creative-thinking/introduction/critical-and-creative-thinking-acrossthe-curriculum , accessed on $27^{\text {th }}$ February, 2017) 